\title{
Dynamic Multi-Stage Gastrointestinal Digestion Model Assessment of Microbial Fermentation Products of Collagen Hydrolysates ${ }^{\dagger}$
}

\author{
Christina E. Larder, Michèle Iskandar and Stan Kubow * \\ School of Human Nutrition, McGill University, 21111 Lakeshore, Ste-Anne-de-Bellevue, QC H9X 3V9, \\ Canada; christina.larder@mail.mcgill.ca (C.E.L.); michele.iskandar@mcgill.ca (M.I.) \\ * Correspondence: stan.kubow@mcgill.ca; Tel.: +1-514-398-7754 \\ + Presented at the The 1st International Electronic Conference on Nutrients - Nutritional and Microbiota \\ Effects on Chronic Disease, 02-15 November 2020; Available online: https://iecn2020.sciforum.net/.
}

Published: 30 October 2020

\begin{abstract}
Proteins, peptides and amino acids (AA) that bypass upper gastrointestinal (GI) digestion can be fermented in the colonic regions. This could lead to microbial production of health promoting short-chain fatty acid (SCFAs). Nitrogenous compounds can also be fermented to generate potentially harmful branched chain fatty acid (BCFAs). As collagen hydrolysate $(\mathrm{CH})$ supplements contain a high peptide content, we evaluated whether peptides that undergo intestinal $\mathrm{CH}$ digestion and microbial fermentation can generate SCFAs and BCFAs. Two bovine-sourced $\mathrm{CH}$ formulations ( $\mathrm{CH}-\mathrm{GL}$ and $\mathrm{CH}-\mathrm{OPT})$ underwent digestive processes and microbial fermentation for $24 \mathrm{~h}$ in a dynamic GI digestion model containing human fecal matter. After $24 \mathrm{~h}, \mathrm{CH}-\mathrm{OPT}$ showed a significant $(p<0.05)$ increase in SCFAs (propionic, butyric and valeric acids) in the ascending colonic vessel with no changes observed with CH-GL. Only CH-OPT showed a significant $(p<0.05)$ increase in BCFAs, also noted in the ascending colon. No significant $(p<0.05)$ changes to SCFAs and BCFAs were observed in the transverse and descending colons for both $\mathrm{CHs}$. These findings demonstrate that $\mathrm{CHs}$ can induce microbial production of SCFAs and BCFAs although this appears to depend on the $\mathrm{CH}$ tested. More studies are needed to determine the physiological significance of these microbial metabolites from intake of $\mathrm{CH}$ supplements.
\end{abstract}

Keywords: nutraceutical; in vitro digestion; collagen hydrolysate; prebiotic; SCFA; BCFA; osteoarthritis; ammonia; hydrogen sulfide; antioxidant

\section{Introduction}

Osteoarthritis (OA) is a debilitating condition, affecting $50 \%$ of people over 75 years old, and accounting for $25 \%$ of visits to family doctors [1-3]. OA results in pain, mobility limitations and significant swelling in joint areas most often in the knees and hips. Risk factors include aging, genetic predisposition, previous injuries, sex, but is also highly associated with metabolic diseases and conditions such as obesity, diabetes, hypertension and dyslipidemia [4-8]. Although in a classical sense, $\mathrm{OA}$ is not often regarded as a metabolic disorder, there have been some insights showing the relationship between OA and increased risk of metabolic syndrome $[9,10]$. Treatment options are limited, although a number of clinical trials have shown that ingestion of collagen hydrolysates $(\mathrm{CHs})$ allows for decreased pain and increased mobility [11-17]. $\mathrm{CH}$ products contain a cocktail of peptides and amino acids (AAs), whereby the peptides can be further broken down into bioactive peptides (BAPs) in the stomach and small intestine [18-21]. It is conceivable that the rich content of peptides and AAs present in $\mathrm{CHs}$ can lead to the generation of microbial nitrogenous fermentation products in the colon, and affect the composition and function of the human gut microbiota community. Such fermentation processes could be important for OA as gut health has been linked to joint health $[7,22]$. 
A recent study on obesity showed a direct link between OA and the gut microbiome, and its effects on systemic inflammation [7]. Therefore, further insights as to how $\mathrm{CH}$ products impact on gut microbial fermentation is warranted, particularly as patients are increasingly utilizing nutraceuticals to mitigate the symptoms of OA $[23,24]$.

Prebiotics are dietary components that can induce beneficial changes in the growth, activity or composition of microorganisms found in the gastrointestinal (GI) tract, otherwise known as the microbiota. Microbial fermentation products of prebiotics have been implicated to provide several health benefits upon the host [25]. Prebiotics have been shown to regulate inflammation, exhibit antioxidant activity as well as reduce symptoms associated with metabolic disorders such as arthritis [7,22,26-28]. As the definition of a prebiotic now includes fermented proteins, peptides and AAs [29], the investigation into the effects of colonic fermentation of $\mathrm{CH}$ products is merited as this could provide additional health benefits.

Short chain fatty acids (SCFAs) are well established products of fermentation of prebiotics and their production is an indicator of a healthy microbial community [30]. SCFA assessment includes acetic, propionic and butyric acids, which are normally present in ratios ranging from 3:1:1 to 10:2:1 [27]. SCFA production is considered as one of the major benefits associated with prebiotics, and the relative abundance of fecal SCFAs has been used as a biomarker of gut health as well as overall systemic health [31,32]. Although only a small fraction of SCFAs are absorbed, there are numerous biological functions attributed to SCFAs that are under active investigation. For example, butyric acid has been implicated in the control of inflammation [33], appetite [34] and liver mitochondrial function [35]. Although less is known about minor SCFAs such as valeric and caproic acids, they also have the potential to affect human health $[36,37]$.

$\mathrm{CH}$ supplementation could also lead to increased microbial production of branched chain fatty acids (BCFAs; isobutyric, isopropionic, isovaleric, isocaproic acid), which are products derived from colonic microbial fermentation of branched-chain amino acids. The health impact of BCFAs is still under debate. Increased production of BCFAs has been associated with prevention of irritable bowel syndrome [38] whereas other studies have increasingly linked exposure to BCFAs with insulin resistance and obesity [39]. To determine the possible production of SCFAs and BCFAs associated with $\mathrm{CH}$ intake, a dynamic multistage computer-controlled GI model was used to observe the production of colonic microbial metabolites from two commercially available $\mathrm{CH}$ products

\section{Materials and Methods}

\subsection{Dynamic In Vitro Gastrointestinal Digestion of Collagen Hydrolysates}

An established dynamic computer-controlled GI model was used to digest the CHs products, which has been previously validated $[40,41]$. The model consists of five bioreactor vessels: stomach, small intestine, ascending colon (ASNC), transverse colon (TRSC, Bangkok, Thailand) and descending colon (DESC). For each vessel, the $\mathrm{pH}$ is continuously measured and adjusted by a computer system, with either the addition of $0.2 \mathrm{M} \mathrm{NaOH}$ or $0.5 \mathrm{M} \mathrm{HCL}$. The temperature of the GI model is kept at $37^{\circ} \mathrm{C}$ and is monitored and controlled by flowing water through double- jacketed reactor vessels in which the GI bioreactors components are found. The model components are attached by plastic tubing and the contents of the reactor vessels are moved by peristaltic pumps. The vessel contents are continuously agitated by stir plates. The colonic vessels were inoculated with fecal matter and allowed to stabilize over a two-week period to allow for optimal bacterial growth. The two bovine-sourced $\mathrm{CH}$ products used for this study were Original Formula ${ }^{\circledR}$ (Genacol, Blainville, QC, Canada) (CH-GL) and Selection (Uniprix, QC, Canada) (CH-OPT). The $\mathrm{CH}$ treatment dose of $1200 \mathrm{mg}$ was added to a gastrointestinal food mixture, as previously described by Sadeghi Ekbatan et al., (2016) and Gaisawat et al., (2019), and which was slowly pumped into the stomach vessel. The treatment dose was based on the daily dose of the Genacol Original Formula ${ }^{\circledR}$ that was shown to reduce joint pain in clinical trials $[11,12,17]$. To our knowledge, no information is available regarding the clinical efficacy of the Selection CH product. An enzyme solution of $\alpha$-amylase (Sigma A3176, St. Louis, MO, USA) prepared in sterile deionized water was added to the GI food mixture to replicate 
salivary digestion. Pepsin (Sigma P7125) prepared in 0.1 M HCL was added to the stomach vessel and $35 \mathrm{~mL}$ of a bile solution composed of pancreatin (Sigma P7545), bile extract (Sigma B8631) and sodium bicarbonate were added to the small intestine, as described by Sadeghi Ekbatan et al., (2016) and Gumienna et al., (2011) [41,42]. Sub-samples from each vessel were obtained at times 0, 8, 16 and $24 \mathrm{~h}$ and filtered using a $0.45 \mu \mathrm{m}$ Millipore syringe-driven filter. Two separate digestion runs were completed for each treatment, with a washout/re-stabilization period of 3 days between treatments. Previous in vitro fermentation experiments have also utilized two separate digestion runs [43].

\subsection{Short and Branched Chain Fatty Acids}

The SCFA and BCFA content was measured using gas chromatograph system equipped with a flame ionization detector (GC-FID) (6890A series, Agilent Technologies, Santa Clara, CA, USA) using an adapted method from Sadeghi Ekbatan et al., (2016) and Gaisawat et al., (2019) [41,44]. Pre-filtered subsamples from the GI model for each colonic vessel were obtained, and then diluted 1:1 with methanol. A $1 \mu \mathrm{L}$ volume was injected into the GI-FID system. An HP-INNOWAS $30 \mathrm{~m}$ fused capillary column (Agilent Technologies, Santa Clara, CA, USA) with a $250 \mu \mathrm{m}$ ID and a film thickness of $0.25 \mu \mathrm{m}$ was used to separate the SCFAs and BCFAs from both the standard mixes and samples. A flow rate of $1 \mathrm{~mL} / \mathrm{min}$ of helium gas was used. The inlet and detector temperatures were set at 220 ${ }^{\circ} \mathrm{C}$ and $230{ }^{\circ} \mathrm{C}$, respectively. The oven temperature was originally set at $150{ }^{\circ} \mathrm{C}$ and held for $10 \mathrm{~min}$ and then increased by $10^{\circ} \mathrm{C} / \mathrm{min}$ to $180^{\circ} \mathrm{C}$ and held for $5 \mathrm{~min}$. SCFAs were identified using a standard mix (46975-U, Sigma Aldrich, St. Louis, MO, USA) and quantified (mM) using an external calibration curve.

\subsection{Statistical Analysis}

Data is reported as mean \pm standard error of the mean (SEM). For each treatment, differences between timepoints was assessed using a one-way ANOVA, followed by Dunnett's post hoc test, using time $0 \mathrm{~h}$ as control. All analysis was completed using JMP (JMP ${ }^{\circledR}$, Version 13.2.1. SAS Institute Inc., Cary, NC, USA) and were considered statistically significant if $p<0.05$.

\section{Results}

\section{SCFAs and BCFAs}

In the ascending colon, no changes in SCFAs were observed after CH-GL digestion (Table 1) whereas individual SCFA profiles showed variability between baseline control (time $0 \mathrm{~h}$ ) after the digestion of CH-OPT (Table 2). Specifically, propionic acid (mM) content increased from a baseline value of $0.50 \pm 0.47$ to $7.59 \pm 0.59$ and $6.53 \pm 1.71$ after $16 \mathrm{~h}$ and $24 \mathrm{~h}$, respectively. Similarly, a significant $(p<0.05)$ increase in butyric acid $(\mathrm{mM})$ was also observed after $16 \mathrm{~h}$ and $24 \mathrm{~h}(6.97 \pm 0.20$ and $5.78 \pm$ 1.21 , respectively) from time $0(2.92 \pm 0.21)$. No significant changes in acetic acid was reported for $\mathrm{CH}-\mathrm{OPT}$, for any timepoint. Valeric acid also increased after 8, 16 and $24 \mathrm{~h}$. No changes in caproic acid or heptanoic acid were observed. For both CHs, no changes in SCFA or BCFA content were observed in the transverse and descending colon compared to baseline (time $0 \mathrm{~h}$ ).

An increase in BCFAs in the ascending colonic reactors was observed only with CH-OPT supplementation (Table 3). Specifically, isovaleric acid $(\mathrm{mM})$ increased from $2.20 \pm 0.09$ at baseline to $3.69 \pm 0.34$ after $16 \mathrm{~h}(p<0.05)$. Although not significant, a trend for an increase in isovaleric acid was observed after $24 \mathrm{~h}(p=0.0588)$.

No increase in BCFA content was observed after digestion of $\mathrm{CH}-\mathrm{GL}$, although a significant decrease in isobutyric acid $(\mathrm{mM})$ was detected (Table 4). Isobutyric acid $(\mathrm{mM})$ decreased from $0.40 \pm$ 0.05 at baseline to $0.19 \pm 0.01$ after $24 \mathrm{~h}(p<0.05)$. A trend for isobutyric acid to decrease relative to control time $0 \mathrm{~h}$ was also observed at $8 \mathrm{~h}(0.23 \pm 0.04)(p=0.0531)$.

Similar to SCFAs, there were no changes in BCFAs in the transverse and descending colon vessels for either $\mathrm{CH}$ treatment. 
Table 1. SCFA for CH-GL at times $0,8,16$ and $24 \mathrm{~h}$ for each colonic region.

\begin{tabular}{|c|c|c|c|c|c|c|}
\hline $\begin{array}{c}\text { Time } \\
\text { (h) }\end{array}$ & $\begin{array}{l}\text { Acetic Acid } \\
(\mathrm{mM})\end{array}$ & $\begin{array}{c}\text { Propionic } \\
\text { Acid (mM) }\end{array}$ & $\begin{array}{l}\text { Butyric Acid } \\
\text { (mM) }\end{array}$ & $\begin{array}{c}\text { Valeric } \\
\text { Acid (mM) }\end{array}$ & $\begin{array}{c}\text { Caproic } \\
\text { Acid (mM) }\end{array}$ & $\begin{array}{l}\text { Heptanoic } \\
\text { Acid (mM) }\end{array}$ \\
\hline \multicolumn{7}{|c|}{ Ascending colon } \\
\hline 0 & $12.43 \pm 4.43$ & $0.08 \pm 0.07$ & $0.05 \pm 0.02$ & $0.00 \pm 0.00$ & $0.00 \pm 0.00$ & $0.00 \pm 0.00$ \\
\hline 8 & $24.83 \pm 1.84$ & $0.16 \pm 0.05$ & $0.05 \pm 0.02$ & $0.00 \pm 0.00$ & $0.00 \pm 0.00$ & $0.00 \pm 0.00$ \\
\hline 16 & $25.17 \pm 1.95$ & $0.18 \pm 0.04$ & $0.05 \pm 0.00$ & $0.00 \pm 0.00$ & $0.00 \pm 0.00$ & $0.00 \pm 0.00$ \\
\hline 24 & $21.48 \pm 0.20$ & $0.22 \pm 0.06$ & $0.05 \pm 0.00$ & $0.00 \pm 0.00$ & $0.01 \pm 0.01$ & $0.00 \pm 0.00$ \\
\hline \multicolumn{7}{|c|}{ Transverse colon } \\
\hline 0 & $3.10 \pm 0.67$ & $1.34 \pm 1.27$ & $4.67 \pm 3.21$ & $1.56 \pm 1.24$ & $0.43 \pm 0.43$ & $0.00 \pm 0.00$ \\
\hline 8 & $6.87 \pm 2.68$ & $1.52 \pm 1.49$ & $5.26 \pm 2.65$ & $1.74 \pm 1.12$ & $0.41 \pm 0.38$ & $0.00 \pm 0.00$ \\
\hline 16 & $10.56 \pm 6.86$ & $1.74 \pm 1.72$ & $3.85 \pm 2.35$ & $1.42 \pm 1.09$ & $0.29 \pm 0.03$ & $0.00 \pm 0.00$ \\
\hline 24 & $12.2 \pm 10.56$ & $1.29 \pm 0.51$ & $2.16 \pm 1.14$ & $0.85 \pm 0.54$ & $0.14 \pm 0.12$ & $0.00 \pm 0.00$ \\
\hline \multicolumn{7}{|c|}{ Descending colon } \\
\hline 0 & $4.50 \pm 1.73$ & $2.08 \pm 1.90$ & $4.56 \pm 3.54$ & $1.09 \pm 1.60$ & $0.46 \pm 0.42$ & $0.00 \pm 0.00$ \\
\hline 8 & $5.56 \pm 1.12$ & $1.75 \pm 1.51$ & $4.70 \pm 1.98$ & $1.80 \pm 0.99$ & $0.41 \pm 0.32$ & $0.00 \pm 0.00$ \\
\hline 16 & $3.83 \pm 0.13$ & $1.49 \pm 1.44$ & $3.83 \pm 2.04$ & $1.49 \pm 0.98$ & $0.40 \pm 0.28$ & $0.00 \pm 0.00$ \\
\hline 24 & $6.80 \pm 2.98$ & $1.51 \pm 1.43$ & $4.63 \pm 0.92$ & $1.68 \pm 0.69$ & $0.38 \pm 0.26$ & $0.00 \pm 0.00$ \\
\hline
\end{tabular}

Table 2. SCFA for CH-OPT at times $0,8,16$ and $24 \mathrm{~h}$ for each colonic region.

\begin{tabular}{|c|c|c|c|c|c|c|}
\hline $\begin{array}{l}\text { Time } \\
\text { (h) }\end{array}$ & $\begin{array}{l}\text { Acetic Acid } \\
\text { (mM) }\end{array}$ & $\begin{array}{l}\text { Propionic } \\
\text { Acid (mM) }\end{array}$ & $\begin{array}{l}\text { Butyric Acid } \\
\text { (mM) }\end{array}$ & $\begin{array}{c}\text { Valeric } \\
\text { Acid }(\mathrm{mM})\end{array}$ & $\begin{array}{c}\text { Caproic } \\
\text { Acid }(\mathrm{mM})\end{array}$ & $\begin{array}{c}\text { Heptanoic } \\
\text { Acid } \\
(\mathrm{mM})\end{array}$ \\
\hline \multicolumn{7}{|c|}{ Ascending colon } \\
\hline 0 & $3.96 \pm 2.18$ & $0.50 \pm 0.47$ & $2.92 \pm 0.21$ & $2.12 \pm 0.05$ & $1.80 \pm 0.22$ & $1.50 \pm 0.08$ \\
\hline 8 & $8.55 \pm 3.71$ & $5.05 \pm 0.43$ & $4.90 \pm 0.26$ & $4.42 \pm 0.21 *$ & $3.65 \pm 0.10$ & $2.87 \pm 0.54$ \\
\hline 16 & $14.12 \pm 2.73$ & $7.59 \pm 0.59 *$ & $6.97 \pm 0.20 *$ & $5.91 \pm 0.37$ * & $4.44 \pm 1.13$ & $3.10 \pm 0.36$ \\
\hline 24 & $14.20 \pm 7.02$ & $6.53 \pm 1.71 *$ & $5.78 \pm 1.21 *$ & $5.07 \pm 0.70 *$ & $3.83 \pm 0.08$ & $3.12 \pm 0.49$ \\
\hline \multicolumn{7}{|c|}{ Transverse colon } \\
\hline 0 & $3.27 \pm 2.13$ & $0.16 \pm 0.03$ & $1.68 \pm 0.38$ & $1.29 \pm 0.21$ & $0.89 \pm 0.03$ & $0.78 \pm 0.16$ \\
\hline 8 & $2.75 \pm 0.41$ & $0.82 \pm 0.72$ & $1.77 \pm 0.50$ & $1.52 \pm 0.26$ & $1.11 \pm 0.47$ & $0.76 \pm 0.13$ \\
\hline 16 & $2.94 \pm 1.46$ & $1.06 \pm 1.00$ & $1.37 \pm 0.18$ & $1.09 \pm 0.03$ & $0.82 \pm 0.23$ & $0.57 \pm 0.08$ \\
\hline 24 & $6.63 \pm 2.54$ & $1.52 \pm 1.46$ & $2.17 \pm 0.18$ & $1.84 \pm 0.12$ & $1.20 \pm 0.37$ & $0.91 \pm 0.05$ \\
\hline \multicolumn{7}{|c|}{ Descending colon } \\
\hline 0 & $2.43 \pm 0.37$ & $0.85 \pm 0.68$ & $2.23 \pm 0.39$ & $1.35 \pm 0.17$ & $0.83 \pm 0.23$ & $0.46 \pm 0.10$ \\
\hline 8 & $4.34 \pm 1.07$ & $1.21 \pm 0.92$ & $3.70 \pm 0.60$ & $2.26 \pm 0.40$ & $1.4 \pm 0.0 .41$ & $0.61 \pm 0.21$ \\
\hline 16 & $3.84 \pm 1.16$ & $0.37 \pm 0.08$ & $3.72 \pm 1.27$ & $2.01 \pm 0.05$ & $1.34 \pm 0.06$ & $0.54 \pm 0.11$ \\
\hline 24 & $3.39 \pm 3.39$ & $0.43 \pm 0.12$ & $3.95 \pm 1.45$ & $2.12 \pm 0.12$ & $1.32 \pm 0.01$ & $0.54 \pm 0.11$ \\
\hline
\end{tabular}


Table 3. BCFA for $\mathrm{CH}-\mathrm{OPT}$ at times $0,8,16$ and $24 \mathrm{~h}$ for each colonic region.

\begin{tabular}{cccc}
\hline Time (h) & Isobutyric Acid (mM) & Isovaleric Acid (mM) & Isocaproic Acid (mM) \\
\hline \multicolumn{5}{c}{ Ascending colon } \\
\hline 0 & $4.27 \pm 1.39$ & $2.20 \pm 0.09$ & $1.56 \pm 0.05$ \\
\hline 8 & $3.80 \pm 0.22$ & $3.20 \pm 0.13$ & $2.66 \pm 0.55$ \\
\hline 16 & $5.19 \pm 0.13$ & $\mathbf{3 . 6 9} \pm \mathbf{0 . 3 4} \mathbf{H}^{*}$ & $2.80 \pm 0.18$ \\
\hline 24 & $4.65 \pm 0.61$ & $\mathbf{2 . 8 1} \pm \mathbf{0 . 1 7}$ & $2.55 \pm 0.47$ \\
\hline 0 & & Transverse colon & $0.64 \pm 0.19$ \\
\hline 8 & $2.67 \pm 1.26$ & $0.86 \pm 0.04$ & $0.59 \pm 0.10$ \\
\hline 16 & $2.20 \pm 0.10$ & $0.98 \pm 0.36$ & $0.52 \pm 0.05$ \\
\hline 24 & $2.20 \pm 0.07$ & $0.82 \pm 0.10$ & $0.73 \pm 0.02$ \\
\hline 0 & $5.64 \pm 0.87$ & $1.09 \pm 0.17$ & $0.40 \pm 0.13$ \\
\hline 8 & & Descending colon & $0.45 \pm 0.18$ \\
\hline 16 & $1.97 \pm 0.09$ & $1.09 \pm 0.07$ & $0.52 \pm 0.17$ \\
\hline 24 & $2.35 \pm 0.11$ & $1.76 \pm 0.17$ & $0.46 \pm 0.13$ \\
\hline
\end{tabular}

Values are expressed as mean \pm SEM in $\mathrm{mM}$. Within a column, ${ }^{*}$ symbol indicates differences from control (Time $0 \mathrm{~h})(p<0.05)$. The symbol ${ }^{+}$indicates a possible trend $(p=0.0588)$.

Table 4. BCFA for CH-GL at times 0, 8, 16 and $24 \mathrm{~h}$ for each colonic region.

\begin{tabular}{|c|c|c|c|}
\hline Time (h) & Isobutyric Acid (mM) & Isovaleric Acid (mM) & Isocaproic Acid (mM) \\
\hline \multicolumn{4}{|c|}{$\begin{array}{l}\text { Ascending colon } \\
\end{array}$} \\
\hline 0 & $0.40 \pm 0.05$ & $0.04 \pm 0.01$ & $0.00 \pm 0.00$ \\
\hline 8 & $0.23 \pm 0.04+$ & $0.04 \pm 0.00$ & $0.00 \pm 0.00$ \\
\hline 16 & $0.26 \pm 0.01$ & $0.04 \pm 0.00$ & $0.01 \pm 0.01$ \\
\hline 24 & $0.19 \pm 0.01 *$ & $0.03 \pm 0.01$ & $0.01 \pm 0.00$ \\
\hline \multicolumn{4}{|c|}{ Transverse colon } \\
\hline 0 & $0.54 \pm 0.17$ & $0.35 \pm 0.18$ & $0.01 \pm 0.01$ \\
\hline 8 & $0.55 \pm 0.09$ & $0.43 \pm 0.22$ & $0.01 \pm 0.01$ \\
\hline 16 & $0.40 \pm 0.23$ & $0.35 \pm 0.27$ & $0.02 \pm 0.01$ \\
\hline 24 & $0.32 \pm 0.10$ & $0.26 \pm 0.16$ & $0.02 \pm 0.01$ \\
\hline \multicolumn{4}{|c|}{ Descending colon } \\
\hline 0 & $0.79 \pm 0.33$ & $0.50 \pm 0.26$ & $0.01 \pm 0.01$ \\
\hline 8 & $1.00 \pm 0.53$ & $0.60 \pm 0.11$ & $0.01 \pm 0.01$ \\
\hline 16 & $0.60 \pm 0.02$ & $0.50 \pm 0.17$ & $0.02 \pm 0.02$ \\
\hline 24 & $0.76 \pm 0.23$ & $0.60 \pm 0.07$ & $0.02 \pm 0.02$ \\
\hline
\end{tabular}

Values are expressed as mean \pm SEM in $\mathrm{mM}$. Within a column, ${ }^{*}$ symbol indicates differences from control (Time $0 \mathrm{~h})(p<0.05)$. The symbol ${ }^{+}$indicates a possible trend $(p=0.0531)$.

\section{Discussion}

To our knowledge, this simulated dynamic GI digestion model study provides the first assessment of the production of SCFAs and BCFAs following fermentation of hydrolyzed collagen by human gut microbiota. Although they were both derived from bovine collagen, only the CH-OPT treatment was associated with an increase in colonic SCFA and BCFA content. This finding is most likely due to differences in the peptide profiles in the two $\mathrm{CH}$ products that can result from differing collagen hydrolysate preparation or purification methods $[45,46]$. In that regard, CH-GL is a formulation that consists of a low molecular weight peptide complex [47]. Thus, the contrasting findings between the two $\mathrm{CH}$ supplements might be due to the putative lower molecular weight peptide complex of $\mathrm{CH}-\mathrm{GL}$ being less amenable to microbial metabolism. Conversely, it appears that 
sufficient amounts of specific peptide sequences in CH-OPT remained intact following upper GI digestive processes to induce microbial generation of SCFAs in terms of butyric, propionic and valeric acids and the BCFA, isovaleric acid. As no changes in SCFAs and BCFAs were observed in the transverse or descending colonic vessels, it is likely that insufficient amounts of peptides reached those vessels to support further microbial fermentation. Although there are no analogous studies involving $\mathrm{CH}$ fermentation, an increase in butyrate and propionate content was observed from fermentation of casein hydrolysates using single stage, anaerobic fermentation chambers inoculated with human fecal matter [48]. In contrast to the present work, the latter study did not include stomach and small intestine digestive processes that can modify peptide profiles prior to their exposure to microbial metabolism. Other reports have shown that wheat arabinogalactan peptides were associated with an increase in SCFAs after $24 \mathrm{~h}$, although this was assessed using in vitro batch fermentation rather than a dynamic GI model system [43]. The multistage dynamic GI model can provide a more accurate representation of human digestive and microbiota metabolism of dietary components as compared to either static digestion models or animal models [49,50].

There are possible metabolic health benefits that might accrue from increased colonic generation of propionic and butyric acid that was associated with CH-OPT supplementation [31,32]. On the other hand, these benefits could be partially offset by the corresponding increase in isovaleric acid seen with the CH-OPT treatment since enhanced gut exposure to BCFAs has been linked to an increased risk for diabetes and obesity [39]. Although not much information is currently known about the health modulatory properties of minor SCFAs, recent research has suggested that fecal valeric acid may serve as an indicator of gut microbial dysbiosis [36]. Hence, the increase in valeric acid concentrations observed with CH-OPT could be indicative of adverse changes in gut microbial composition. An additional potential concern in relation to $\mathrm{OA}$ are reports that fecal valeric acid is positively correlated with the pro-inflammatory C-reactive protein in patients with ischemic stroke [51]. Conversely, the conjugated base of valeric acid has been associated with enhancing interleukin10 production and suppressing Th17 cells, which could provide anti-inflammatory benefits [52]. The immunomodulatory effects of valeric acid needs further investigation, particularly in relation to OA and rheumatoid arthritis as these are conditions associated with an increase in joint and whole body proinflammatory processes [53]. Interestingly, the lack of effect of the CH-GL on the SCFA and BCFA production indicates that this supplement does not have either prebiotic or dysbiotic properties in contrast to $\mathrm{CH}-\mathrm{OPT}$.

\section{Conclusions}

To date, there is limited information regarding the effects of food-derived peptides on the gut microbiome and microbial fermentation products such as SCFAs and BCFAs. The present study provides the first evidence that CHs can lead to the generation of SCFAs and BCFAs but that this microbial metabolic activity appears to be dependent on the nature of the $\mathrm{CH}$ tested. The application of peptidomics to characterize the heterogeneity of peptides generated via digestive and fermentative processes could provide more insight regarding the peptide sequences involved in the colonic microbial fermentation. A recent review has highlighted that long-term dietary choices, such as greater protein content, could exert effects on GI microbial populations, which has implications towards development of metabolic diseases such as obesity and diabetes [29]. This review emphasized that important knowledge gaps exist concerning dietary protein-mediated generation of colonic microbial molecules that could exert bioactivities towards gut inflammation and permeability. Accordingly, it is possible that $\mathrm{CH}$ supplements, which contain a rich content of peptides, can impact the structure and function of gut microbial communities. The dynamic GI model platforms, such the one utilized in the present study, can be a useful tool to further investigate the impact of $\mathrm{CH}$ supplementation on the gut microbiome and other biomarkers of gut health in order to more fully understand the impact these nutraceuticals on GI and systemic health. 
Author Contributions: Conceptualization, methodology was completed by C.E.L., M.I. and S.K. Data curation, formal analysis, writing-original draft preparation was done by C.E.L. Validation, project administration, writing - review and editing was completed by M.I. and S.K. Resources, supervision, funding acquisition was done by S.K. All authors have read and agreed to the published version of the manuscript.

Funding: The present study was supported by a MITACS Accelerate Program PhD studentship (IT10556) collaboration between McGill University and Genacol Canada Corporation and the Collaborative Research Development Grant Program from the Natural Sciences and Engineering Council of Canada to S.K. (535744 -18).

Acknowledgments: We would like to thank Mohd Baasir Gaisawat for his support in the operation of the dynamic GI model.

Conflicts of Interest: The authors report no conflict of interest.

\section{References}

1. Lane, N.E.; Shidara, K.; Wise, B.L. Osteoarthritis year in review 2016: Clinical. Osteoarthr. Cartil. 2017, 25, 209-215.

2. Bello, A.E.; Oesser, S. Collagen hydrolysate for the treatment of osteoarthritis and other joint disorders:A review of the literature. Curr. Med. Res. Opin. 2006, 22, 2221-2232.

3. Li, M.H.; Xiao, R.; Li, J.B.; Zhu, Q. Regenerative approaches for cartilage repair in the treatment of osteoarthritis. Osteoarthr. Cartil. 2017, 25, 1577-1587.

4. Eymard, F.; Parsons, C.; Edwards, M.H.; Petit-Dop, F.; Reginster, J.Y.; Bruyère, O.; Richette, P.; Cooper, C.; Chevalier, X. Diabetes is a risk factor for knee osteoarthritis progression. Osteoarthr. Cartil. 2015, 23, 851859, doi:10.1016/j.joca.2015.01.013.

5. Singh, G.; Miller, J.D.; Lee, F.H.; Pettitt, D.; Russell, M.W. Prevalence of cardiovascular disease risk factors among us adults with self-reported osteoarthritis: Data from the third national health and nutrition examination survey. Am. J. Manag. Care 2002, 8, S383-S391.

6. Baudart, P.; Louati, K.; Marcelli, C.; Berenbaum, F.; Sellam, J. Association between osteoarthritis and dyslipidaemia: A systematic literature review and meta-analysis. RMD Open 2017, 3, e000442, doi:10.1136/rmdopen-2017-000442.

7. Schott, E.M.; Farnsworth, C.W.; Grier, A.; Lillis, J.A.; Soniwala, S.; Dadourian, G.H.; Bell, R.D.; Doolittle, M.L.; Villani, D.A.; Awad, H.; et al. Targeting the gut microbiome to treat the osteoarthritis of obesity. JCI Insight 2018, 3, e95997, doi:10.1172/jci.insight.95997.

8. Veronese, N.; Cooper, C.; Reginster, J.-Y.; Hochberg, M.; Branco, J.; Bruyère, O.; Chapurlat, R.; Al-Daghri, N.; Dennison, E.; Herrero-Beaumont, G.; et al. Type 2 diabetes mellitus and osteoarthritis. Semin. Arthritis Rheum. 2019, 49, 9-19, doi:10.1016/j.semarthrit.2019.01.005.

9. Sellam, J.; Berenbaum, F. Is osteoarthritis a metabolic disease? Jt. Bone Spine 2013, 80, 568-573, doi:10.1016/j.jbspin.2013.09.007.

10. Kluzek, S.; Newton, J.L.; Arden, N.K. Is osteoarthritis a metabolic disorder? Br. Med. Bull. 2015, 115, 111121, doi:10.1093/bmb/ldv028.

11. Bernado, M.L.R.; Azarcon, J.A.C. A randomized control trial on the effects of oral collagen treatment on the medial knee joint space and functional outcome among veterans medical center patients diagnosed with osteoarthritis of the knee. Philipp. Acad. Rehabil. Med. Process. 2012, 4, 1-8.

12. Bruyère, O.; Zegels, B.; Leonori, L.; Rabenda, V.; Janssen, A.; Bourges, C.; Reginster, J.Y. Effect of collagen hydrolysate in articular pain: A 6-month randomized, double-blind, placebo controlled study. Complement. Ther. Med. 2012, 20, 124-130.

13. Kumar, S.; Sugihara, F.; Suzuki, K.; Inoue, N.; Venkateswarathirukumara, S. A double-blind, placebocontrolled, randomised, clinical study on the effectiveness of collagen peptide on osteoarthritis. J. Sci. Food Agric. 2015, 95, 702-707.

14. Zdzieblik, D.; Gollhofer, A.; Konig, D.; Oesser, S.; Baumstark, M.W.; Konig, D. Collagen peptide supplementation in combination with resistance training improves body composition and increases muscle strength in elderly sarcopenic men: A randomised controlled trial. Br. J. Nutr. 2015, 114, 1237-1245.

15. Zdzieblik, D.; Oesser, S.; Gollhofer, A.; König, D. Improvement of activity-related knee joint discomfort following supplementation of specific collagen peptides. Appl. Physiol. Nutr. Metab. 2017, 42, 588-595, doi:10.1139/apnm-2016-0390. 
16. Benito-Ruiz, P.; Camacho-Zambrano, M.M.; Carrillo-Arcentales, J.N.; Mestanza-Peralta, M.A.; VallejoFlores, C.A.; Vargas-López, S.V.; Villacís-Tamayo, R.A.; Zurita-Gavilanes, L.A. A randomized controlled trial on the efficacy and safety of a food ingredient, collagen hydrolysate, for improving joint comfort. Int. J. Food Sci. Nutr. 2009, 60, 99-113.

17. Feliciano, D.D.S.; Gonzalex-Suarez, C.B.; Bernardo-Bueno, M.M.; Malvar, A.K.G.; Cua, R.C.A.; Tan-Sales, B.G.K.; Aycardo, S.M.O.; Tan-Ong, M.; Chan, R.; Reyes, F.D.L. Effect of collagen hydrolysate as adjuvant treatment to exercise for knee osteoarthiritis. Philipp. Acad. Rehabil. Med. 2017, 9, 4-15.

18. Skov, K.; Oxfeldt, M.; Thøgersen, R.; Hansen, M.; Bertram, H.C. Enzymatic hydrolysis of a collagen hydrolysate enhances postprandial absorption rate-a randomized controlled trial. Nutrients 2019, 11, doi:10.3390/nu11051064.

19. Alemán, A.; Gómez-Guillén, M.C.; Montero, P. Identification of ace-inhibitory peptides from squid skin collagen after in vitro gastrointestinal digestion. Food Res. Int. 2013, 54, 790-795.

20. Guo, L.; Harnedy, P.A.; Zhang, L.; Li, B.; Zhang, Z.; Hou, H.; Zhao, X.; FitzGerald, R.J. In vitro assessment of the multifunctional bioactive potential of alaska pollock skin collagen following simulated gastrointestinal digestion. J. Sci. Food Agric. 2015, 95, 1514-1520, doi:10.1002/jsfa.6854.

21. Fu, Y.; Therkildsen, M.; Aluko, R.E.; Lametsch, R. Exploration of collagen recovered from animal byproducts as a precursor of bioactive peptides: Successes and challenges. Crit. Rev. Food Sci. Nutr. 2019, 59, 2011-2027, doi:10.1080/10408398.2018.1436038.

22. Dorozynska, I.; Majewska-Szczepanik, M.; Marcinska, K.; Szczepanik, M. Partial depletion of natural gut flora by antibiotic aggravates collagen induced arthritis (cia) in mice. Pharmacol. Rep. 2014, 66, 250-255.

23. Sirico, F.; Salvatore, M.; Clotilde, C.; Rocco, S.; Stefania, M.; Franca Di, M.; Daria, N. Habits and beliefs related to food supplements: Results of a survey among italian students of different education fields and levels. PLoS ONE 2018, 13, e0191424, doi:10.1371/journal.pone.0191424.

24. Dickinson, A.; MacKay, D.; Wong, A. Consumer attitudes about the role of multivitamins and other dietary supplements: Report of a survey. Nutr. J. 2015, 14, 66, doi:10.1186/s12937-015-0053-9.

25. Roberfroid, M.; Gibson, G.R.; Hoyles, L.; McCartney, A.L.; Rastall, R.; Rowland, I.; Wolvers, D.; Watzl, B.; Szajewska, H.; Stahl, B.; et al. Prebiotic effects: Metabolic and health benefits. Br. J. Nutr. 2010, 104 (Suppl. S2), S1-S63, doi:10.1017/s0007114510003363.

26. Liu, X.; Zeng, B.; Zhang, J.; Li, W.; Mou, F.; Wang, H.; Zou, Q.; Zhong, B.; Wu, L.; Wei, H.; et al. Role of the gut microbiome in modulating arthritis progression in mice. Sci. Rep. 2016, 6, 30594.

27. Rowland, I.; Gibson, G.; Heinken, A.; Scott, K.; Swann, J.; Thiele, I.; Tuohy, K. Gut microbiota functions: Metabolism of nutrients and other food components. Eur. J. Nutr. 2017, 57, 1-24.

28. Peng, M.; Biswas, D. Short chain and polyunsaturated fatty acids in host gut health and foodborne bacterial pathogen inhibition. Crit. Rev. Food Sci. Nutr. 2017, 57, 3987-4002.

29. Diether, N.E.; Willing, B.P. Microbial fermentation of dietary protein: An important factor in diet-microbehost interaction. Microorganisms 2019, 7, 19, doi:10.3390/microorganisms7010019.

30. Nyangale, E.P.; Mottram, D.S.; Gibson, G.R. Gut microbial activity, implications for health and disease: The potential role of metabolite analysis. J. Proteome Res. 2012, 11, 5573-5585.

31. Abdul Rahim, M.B.H.; Chilloux, J.; Martinez-Gili, L.; Neves, A.L.; Myridakis, A.; Gooderham, N.; Dumas, M.-E. Diet-induced metabolic changes of the human gut microbiome: Importance of short-chain fatty acids, methylamines and indoles. Acta Diabetol. 2019, 56, 493-500, doi:10.1007/s00592-019-01312-x.

32. Ríos-Covián, D.; Ruas-Madiedo, P.; Margolles, A.; Gueimonde, M.; de los Reyes-Gavilán, C.G.; Salazar, N. Intestinal short chain fatty acids and their link with diet and human health. Front. Microbiol. 2016, 7, 185.

33. Matt, S.M.; Allen, J.M.; Lawson, M.A.; Mailing, L.J.; Woods, J.A.; Johnson, R.W. Butyrate and dietary soluble fiber improve neuroinflammation associated with aging in mice. Front. Immunol. 2018, 9, 1832, doi:10.3389/fimmu.2018.01832.

34. Li, Z.; Yi, C.X.; Katiraei, S.; Kooijman, S.; Zhou, E.; Chung, C.K.; Gao, Y.; van den Heuvel, J.K.; Meijer, O.C.; Berbée, J.F.P.; et al. Butyrate reduces appetite and activates brown adipose tissue via the gut-brain neural circuit. Gut 2018, 67, 1269-1279, doi:10.1136/gutjnl-2017-314050.

35. Mollica, M.P.; Mattace Raso, G.; Cavaliere, G.; Trinchese, G.; De Filippo, C.; Aceto, S.; Prisco, M.; Pirozzi, C.; Di Guida, F.; Lama, A.; et al. Butyrate regulates liver mitochondrial function, efficiency, and dynamics in insulin-resistant obese mice. Diabetes 2017, 66, 1405-1418, doi:10.2337/db16-0924. 
36. Chang, Y.; Chen, Y.; Zhou, Q.; Wang, C.; Chen, L.; Di, W.; Zhang, Y. Short-chain fatty acids accompanying changes in the gut microbiome contribute to the development of hypertension in patients with preeclampsia. Clin. Sci. 2020, 134, 289-302, doi:10.1042/cs20191253.

37. Saresella, M.; Marventano, I.; Barone, M.; La Rosa, F.; Piancone, F.; Mendozzi, L.; d'Arma, A.; Rossi, V.; Pugnetti, L.; Roda, G.; et al. Alterations in circulating fatty acid are associated with gut microbiota dysbiosis and inflammation in multiple sclerosis. Front. Immunol. 2020, 11, doi:10.3389/fimmu.2020.01390.

38. Sheflin, A.M.; Borresen, E.C.; Wdowik, M.J.; Rao, S.; Brown, R.J.; Heuberger, A.L.; Broeckling, C.D.; Weir, T.L.; Ryan, E.P. Pilot dietary intervention with heat-stabilized rice bran modulates stool microbiota and metabolites in healthy adults. Nutrients 2015, 7, 1282-1300.

39. Utzschneider, K.M.; Kratz, M.; Damman, C.J.; Hullar, M. Mechanisms linking the gut microbiome and glucose metabolism. J. Clin. Endocrinol. Metab. 2016, 101, 1445-1454.

40. Kubow, S.; Iskandar, M.M.; Melgar-Bermudez, E.; Sleno, L.; Sabally, K.; Azadi, B.; How, E.; Prakash, S.; Burgos, G.; Felde, T.Z. Effects of simulated human gastrointestinal digestion of two purple-fleshed potato cultivars on anthocyanin composition and cytotoxicity in colonic cancer and non-tumorigenic cells. Nutrients 2017, 9, 953, doi:10.3390/nu9090953.

41. Sadeghi Ekbatan, S.; Sleno, L.; Sabally, K.; Khairallah, J.; Azadi, B.; Rodes, L.; Prakash, S.; Donnelly, D.J.; Kubow, S. Biotransformation of polyphenols in a dynamic multistage gastrointestinal model. Food Chem. 2016, 204, 453-462.

42. Gumienna, M.; Lasik, M.; Czarnecki, Z. Bioconversion of grape and chokeberry wine polyphenols during simulated gastrointestinal in vitro digestion. Int. J. Food Sci. Nutr. 2011, 62, 226-233.

43. Harris, S.; Powers, S.; Monteagudo-Mera, A.; Kosik, O.; Lovegrove, A.; Shewry, P.; Charalampopoulos, D. Determination of the prebiotic activity of wheat arabinogalactan peptide (agp) using batch culture fermentation. Eur. J. Nutr. 2020, 59, 297-307, doi:10.1007/s00394-019-01908-7.

44. Gaisawat, M.B.; MacPherson, C.W.; Tremblay, J.; Piano, A.; Iskandar, M.1.M.; Tompkins, T.A.; Kubow, S. Probiotic supplementation in a clostridium difficile-infected gastrointestinal model is associated with restoring metabolic function of microbiota. Microorganisms 2019, 8, 60, doi:10.3390/microorganisms8010060.

45. Ao, J.; Li, B. Amino acid composition and antioxidant activities of hydrolysates and peptide fractions from porcine collagen. Food Sci. Technol. Int. 2012, 18, 425-434.

46. Sun, L.; Chang, W.; Ma, Q.; Zhuang, Y. Purification of antioxidant peptides by high resolution mass spectrometry from simulated gastrointestinal digestion hydrolysates of alaska pollock (theragra chalcogramma) skin collagen. Mar. Drugs 2016, 14, 186.

47. Michaud, G. Use of Low Molecular Weight Collagen Hydrolysate for Preventing and/or Reducting Joint Pain, Lateral Meniscal Protusion and/or Improving Cartilage Abrasion Grade. U.S. Patent 20200078435, 12 March 2020.

48. Walker, A.W.; Duncan, S.H.; McWilliam Leitch, E.C.; Child, M.W.; Flint, H.J. Ph and peptide supply can radically alter bacterial populations and short-chain fatty acid ratios within microbial communities from the human colon. Appl. Environ. Microbiol. 2005, 71, 3692-3700.

49. Dupont, D.; Alric, M.; Blanquet-Diot, S.; Bornhorst, G.; Cueva, C.; Deglaire, A.; Denis, S.; Ferrua, M.; Havenaar, R.; Lelieveld, J.; et al. Can dynamic in vitro digestion systems mimic the physiological reality? Crit. Rev. Food Sci. Nutr. 2019, 59, 1546-1562.

50. La Fata, G.; Rastall, R.A.; Lacroix, C.; Harmsen, H.J.M.; Mohajeri, M.H.; Weber, P.; Steinert, R.E. Recent development of prebiotic research-statement from an expert workshop. Nutrients 2017, 9, 1376, doi:10.3390/nu9121376.

51. Yamashiro, K.; Tanaka, R.; Urabe, T.; Ueno, Y.; Yamashiro, Y.; Nomoto, K.; Takahashi, T.; Tsuji, H.; Asahara, T.; Hattori, N. Gut dysbiosis is associated with metabolism and systemic inflammation in patients with ischemic stroke. PLoS ONE 2017, 12, e0171521, doi:10.1371/journal.pone.0171521.

52. Luu, M.; Pautz, S.; Kohl, V.; Singh, R.; Romero, R.; Lucas, S.; Hofmann, J.; Raifer, H.; Vachharajani, N.; Carrascosa, L.C.; et al. The short-chain fatty acid pentanoate suppresses autoimmunity by modulating the metabolic-epigenetic crosstalk in lymphocytes. Nat. Commun. 2019, 10, 760, doi:10.1038/s41467-019-087112. 
53. Berenbaum, F. Osteoarthritis as an inflammatory disease (osteoarthritis is not osteoarthrosis!). Osteoarthr. Cartil. 2013, 21, 16-21, doi:10.1016/j.joca.2012.11.012.

Publisher's Note: MDPI stays neutral with regard to jurisdictional claims in published maps and institutional affiliations.

(C) 2020 by the authors. Submitted for possible open access publication under the terms and conditions of the Creative Commons Attribution (CC BY) license (http://creativecommons.org/licenses/by/4.0/). 